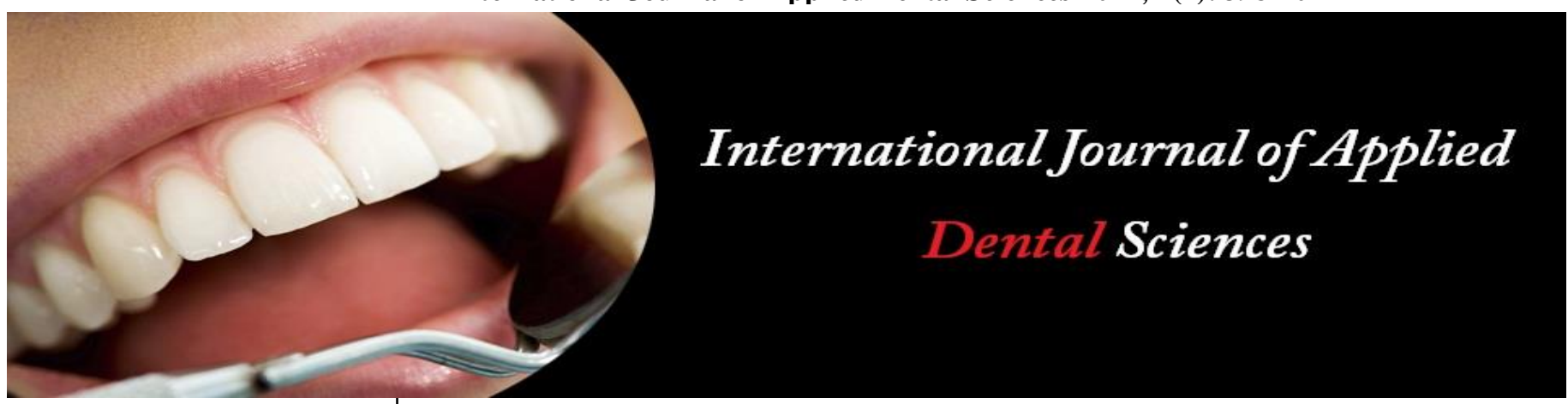

ISSN Print: 2394-7489

ISSN Online: 2394-7497

IJADS 2021; 7(1): 398-401

(C) 2021 IJADS

www.oraljournal.com

Received: 14-02-2021

Accepted: 04-03-2021

Vishakha Kashyap

Final Year Post Graduate

Student, Department of

Paediatric and Preventive

Dentistry, B.J.S. Dental College,

Hospital and Research Institute;

Ludhiana, Punjab, India

\section{Bharat Suneja}

Professor and Head, Department of Paediatric and Preventive

Dentistry, B.J.S. Dental College, Hospital and Research Institute; Ludhiana, Punjab, India

\section{Jasvir Kaur}

Reader, Department of

Paediatric and Preventive

Dentistry, B.J.S. Dental College,

Hospital and Research Institute;

Ludhiana, Punjab, India

\section{Amanpreet Singh}

Reader, Department of

Paediatric and Preventive

Dentistry, B.J.S. Dental College,

Hospital and Research Institute;

Ludhiana, Punjab, India

\section{Sunaina Jodhka}

Professor, Department of

Paediatric and Preventive

Dentistry, B.J.S. Dental College,

Hospital and Research Institute;

Ludhiana, Punjab, India

\section{Corresponding Author:}

Vishakha Kashyap

Final Year Post Graduate

Student, Department of

Paediatric and Preventive

Dentistry, B.J.S. Dental College,

Hospital and Research Institute

Ludhiana, Punjab, India

\section{Comparison of patient and parental preference between nitrous oxide sedation and conventional behavior management technique for dental treatment: A randomized crossover study}

\author{
Vishakha Kashyap, Bharat Suneja, Jasvir Kaur, Amanpreet Singh and \\ Sunaina Jodhka
}

DOI: https://doi.org/10.22271/oral.2021.v7.i1f.1159

Abstract

Aim: To Compare patient and parental preference between nitrous oxide sedation and conventional behaviour management technique for dental treatment.

Material and Methods: This cross-over split mouth study design was performed on 30 children (6-12 years old) who require a bilateral treatment involving inferior alveolar nerve block. 15 children were enrolled in a group A \& 15 children in a group B. Thereafter, the outcome of preference of technique was assessed by parent and child after both techniques were performed.

Results: The collected data was statistically analysed. The majority of children and parents preferred nitrous oxide inhalation sedation to conventional behaviour management techniques.

Conclusion: Study concludes that nitrous oxide was preferred by both children and their parents over conventional behavior management techniques.

Keywords: Conventional behaviour management techniques, Nitrous oxide-oxygen sedation, Inferior alveolar nerve block, parents, children

\section{Introduction}

The success of any dental treatment provided by a paediatric dentist depends not only on the co-operation level of a child but also on parental factors such as child-parent relationship, parental anxiety, parent's perceptions for child's behaviour in the dental operatory. This can be especially true when sedation is employed to manage child behaviour.

Although there has been an increase knowledge and a for sedation techniques especially, nitrous oxide-oxygen (NIOS) among dentists ${ }^{[1]}$, most dentists who treat children still employ only the conventional techniques to manage child behaviour, particularly in India. The acceptability of this technique by both children and their parents can be a possible concern to the practicing dentist. In the process of choosing to get the dental treatment with or without nitrous oxide inhalation sedation, the parent and the child's perception of this pharmacological intervention is of paramount importance ${ }^{[2,3]}$. A number of clinical studies have been published which compare conscious sedation and combinations of cognitive behavioural strategies for their effectiveness, but the literature on acceptance of conscious sedation by parents and children, especially in our country is not adequate ${ }^{[1,4]}$. Most of published research is based on questionnaire studies and clinical studies in comparison are few ${ }^{[5,7]}$. The preference of the parent and the child for choosing NOIS over other techniques has not been reported.

The present study is designed as a cross over study wherein the acceptance and preference were assessed after the child was treated with and without inhalation sedation. The purpose of this clinical study was to compare the preference of children and their parents between $\mathrm{N}_{2} \mathrm{O}$ / $\mathrm{O}_{2}$ inhalation sedation and conventional behaviour management techniques after completion of dental procedures under inferior alveolar block when the child was managed behaviourally using both these techniques. 


\section{Materials and Method}

30 subjects reported to the department of paediatric dentistry, BJS dental college were selected through screening for inclusion and exclusion criteria.

\section{Inclusion Criteria}

1. Age 6-12 yrs

2. Subjects belong to American society of anesthesiologists ASA-1 Category

3. Subjects needing dental treatment which required a bilateral inferior alveolar nerve block

\section{Exclusion Criteria}

Clinical conditions contra-indicating to the use of $\mathrm{N}_{2} \mathrm{O} / \mathrm{O}_{2}$ or with known allergy to lignocaine.

\section{Parental Consent}

A written consent for inhalation sedation and for the participation of the child in the study was obtained from each parent. The parents/guardians of the children were given a complete verbal explanation about the procedure, need and safety of $\mathrm{N}_{2} \mathrm{O} / \mathrm{O}_{2}$ inhalation sedation.

\section{Randomization}

Thirty chits were kept inside a box. Every child enrolled in the study was asked to pick up a chit and accordingly the child was allocated either group A or group B.

Group A (odd) consisted of children who in the first visit were to be treated under nitrous oxide inhalation sedation (NIOS) and in second visit were to be managed using conventional behaviour management techniques (CBT).

Similarly, Group B (even) consisted of children who in the first visit were to be managed with conventional behaviour management techniques and in second visit was to be managed using nitrous oxide inhalation sedation.

A minimum of fifteen day interval period was kept between $1^{\text {st }}$ and $2^{\text {nd }}$ visit.

\section{Armamentarium}

1. Inhalation sedation unit-Matrx Quantiflex MDM ANALOGUE relative analgesia machine (Matrx Medical Inc., Orchard Park, New York, USA) was used for the study

2. Pulse oximeter - It was used to continuously assess the oxygen saturation $\left(\mathrm{SPO}_{2}\right)$ and pulse rate throughout the procedure

3. Different sizes of nasal hood

4. Local anaesthesia (2\% lignocaine hydrochloride with $1: 100,000$ adrenaline)

5. Lignocaine hydrochloride gel (LOX-2\% gel)

\section{Method}

Whenever sedation was employed, it was done using a standardised technique as described by textbook of clark ${ }^{[8]}$.

The technique was described to the patient as per the child's level of understanding using euphemisms.

A flow rate (liter per minute) of $100 \%$ oxygen was established, and the nasal hood was secured on the patient's nose. The hood was adjusted suitably for child's comfort. The appropriate flow rate was established while the child was breathing $100 \%$ oxygen $(5-6 \mathrm{l} / \mathrm{min}$ ) for $5 \mathrm{~min}$. Nasal breathing was encouraged, and the nasal hood was checked for leaks. The reservoir bag was monitored that it should remain uniform during breathing and should not expand or shrink. The percentage of $\mathrm{N}_{2} \mathrm{O}$ was started initially at $10 \%$. Then, it was titrated in approximately $10 \%$ increment rise every $60 \mathrm{~s}$. The $\mathrm{N}_{2} \mathrm{O}$ was titrated up to $30-45 \%$. Constant communication with the child including physical, visual and verbal contact was maintained. Once the objective signs of sedation were observed (child became relaxed, spontaneous movements decreased, abduction of feet); the child was questioned how as to how he or she was feeling. When the child stated that he or she was feeling pleasant and relaxed, it was concluded that the ideal level of clinical sedation was achieved and the dental treatment was initiated. As the treatment ended and the need for sedation requirement ceased, the $\mathrm{N}_{2} \mathrm{O}$ flow was tapered and the child was given $100 \%$ oxygen at a flow rate equivalent to the established rate for him or her 3-5 min before terminating the sedation process to prevent diffusion hypoxia and allow complete recovery from sedation. The child was discharged if the pre-sedation level of responsiveness or a level as close as possible to normal was achieved ${ }^{[9]}$.

Whenever conventional behaviour management technique was employed, it was done utilizing the non-pharmacologic behaviour management techniques as described in the pediatric dental literature with combination of Tell Show Do, euphemisms, modelling and distraction ${ }^{[10]}$.

\section{Local anaesthesia administration}

All the children selected for the study needed pulp therapy, extraction to be done under inferior alveolar nerve block. Children were explained regarding the procedure using euphemisms. Inferior alveolar nerve block was performed using the standard technique after application of topical anaesthesia. A volume of $1.5 \mathrm{ml}$ of $2 \%$ lignocaine hydrochloride with 1:100,000 adrenaline (Neon, India) was used through a 30 gauge, $25 \mathrm{~mm}$ long needle. Administration of sedation and treatment of patient was performed by same operator over both the visits. Parent was allowed to view the child during the treatment under both visits. After the dental procedure was completed. At the end of $2^{\text {nd }}$ visit, both child and parent independently assessed that preferred mode of treatment for subsequent dental visit. All the data was recorded and statistically analysed.

\section{Results}

The study was carried out on age group 6-12 years. The minimum age in entire sample $(n=30)$ group was 6 years and maximum age was 11 years. The average mean age was 7.6 years with a standard deviation 1.3.

Parent and Child Preference: Preference of conventional behaviour management techniques and nitrous oxide sedation techniques were assessed by parents and children. The response was recorded after completion of treatment after both visits. Overall, it was seen that $96.7 \%$ parents preferred nitrous oxide sedation over conventional behaviour management techniques for future dental visits. It was seen that $86 \%$ of children preferred the nitrous oxide sedation over CBT for future dental visits. (Table 1).

Table 1: Parent and Children Preferences

\begin{tabular}{|c|c|c|}
\hline Sedation Type & Parent Preference & Child Preference \\
\hline \multirow{2}{*}{ NIOS } & 29 & 26 \\
\cline { 2 - 3 } & $96.7 \%$ & $86.7 \%$ \\
\hline \multirow{2}{*}{ CBT } & 1 & 4 \\
\cline { 2 - 3 } & $3.3 \%$ & $13.3 \%$ \\
\hline Total & 30 & 30 \\
\hline
\end{tabular}


During comparison of parents and children preferences for both the group. Further within the group A, it was seen that 14 out of 15 parents preferred nitrous oxide sedation over conventional behaviour management techniques for future dental visits. For Group B all parents preferred nitrous oxide sedation and 13 out of 15 children preferred the nitrous oxide sedation over CBT for future dental visits in both the groups. (Table 2)

Table 2: Comparison of parent and children preferences for both the groups (A - B)

\begin{tabular}{|c|c|c|c|c|}
\hline \multirow{2}{*}{\multicolumn{2}{|c|}{ Sedation Type }} & \multicolumn{2}{|c|}{ Groups } & \multirow{3}{*}{$\begin{array}{c}\text { Total } \\
26\end{array}$} \\
\hline & & \multirow{2}{*}{$\begin{array}{c}\text { Group A } \\
13 \\
\end{array}$} & \multirow{2}{*}{$\begin{array}{c}\text { Group B } \\
13\end{array}$} & \\
\hline \multirow{4}{*}{$\begin{array}{c}\text { Child } \\
\text { Preference }\end{array}$} & \multirow{2}{*}{ NIOS } & & & \\
\hline & & $86.7 \%$ & $86.7 \%$ & $86.7 \%$ \\
\hline & CBT & 2 & 2 & 4 \\
\hline & & $13.3 \%$ & $13.3 \%$ & $13.3 \%$ \\
\hline \multicolumn{2}{|c|}{ Total } & 15 & 15 & 30 \\
\hline
\end{tabular}

\begin{tabular}{|c|c|c|c|c|}
\hline \multirow{2}{*}{\multicolumn{2}{|c|}{ Sedation Type }} & \multicolumn{2}{|c|}{ Groups } & \multirow{3}{*}{$\begin{array}{c}\text { Total } \\
29\end{array}$} \\
\hline & & \multirow{2}{*}{$\begin{array}{c}\text { Group A } \\
14\end{array}$} & \multirow{2}{*}{$\begin{array}{c}\text { Group B } \\
15\end{array}$} & \\
\hline \multirow{4}{*}{$\begin{array}{c}\text { Parent } \\
\text { Preference }\end{array}$} & \multirow{2}{*}{ NIOS } & & & \\
\hline & & $93.3 \%$ & $100.0 \%$ & $96.7 \%$ \\
\hline & \multirow{2}{*}{ CBT } & 1 & 0 & 1 \\
\hline & & $6.7 \%$ & $.0 \%$ & $3.3 \%$ \\
\hline \multicolumn{2}{|c|}{ Total } & 15 & 15 & 30 \\
\hline
\end{tabular}

\section{Discussion}

Nitrous oxide inhalation sedation is now being increasingly utilised in pediatric dentistry. It has been frequently reported, that it allows the patient to tolerate unpleasant procedures by reducing or relieving anxiety, discomfort or pain [11, 12]. Nitrous oxide/oxygen inhalation sedation has an excellent safety record and has been described as a safe and an effective agent for providing pharmacological guidance of behaviour in children ${ }^{[13]}$.

The present cross over clinical study compared patient and parental acceptance of nitrous oxide sedation and conventional behaviour management technique for dental treatment. It was conducted on children between 6 to 12 years (mean age 7.6 years). At this age children can understand the verbal explanation given to them regarding nasal hood, breathing instructions etc. Various studies have shown that acceptance of inhalation route among children is better as they grow older. According to literature reviews, children above the age of 7 are indicated for sedation as the child is mature enough to understand the procedure ${ }^{[14,15]}$.

Some previously reported surveys have also reported a high acceptance of NIOS. According to a survey in 2016, investigated the attitude of parents towards NIOS, and it was concluded that most parents in Kuwait are unaware of nitrous oxide sedation as a Behaviour Management Technique, but more than half of them accepted its usage for their children upon their dentist's advice and recommendation ${ }^{[16]}$. In 2018, an epidemiological questionare study was conducted on north Indian children of age group 2-5 years, parents or guardian (Himachal Pradesh) to find out the awareness, knowledge and attitude towards conscious sedation. It concludes that the parents feel sedation is safe in the dental office ${ }^{[17]}$.

In the present clinical study, patient and parental preference of one technique over the other was recorded after the child underwent dental treatment utilising both the techniques. To the best of our knowledge, none of the published studies so far, have checked for preference in this manner. The results were hugely in favour of nitrous-oxide, which was the preference for the majority. $96.7 \%$ parents and $86.7 \%$ children would have preferred sedation with nitrous oxide in their future dental visits. The reason for such a large number of parents preferring nitrous could be that they saw that the child was less anxious and relatively pain free during and after dental treatment. The preference for nitrous was slightly lesser for children themselves. Irritation due to the nasal mask being in place for the entire duration of treatment could be the probable cause.

Nitrous oxide inhalation sedation allows operator to provide a positive experience and contributes in preserving the trust of the child as well as his parent's. The $\mathrm{N}_{2} \mathrm{O} / \mathrm{O}_{2}$ inhalation sedation is not meant to replace the trust building communication that is inherent to a good patient clinician relationship, nor is it meant to replace the conventional behaviour management techniques in entirety. But it can serve as a very useful adjunct and can provide the missing link that the paediatric dentist might need to achieve cooperative behaviour from their child patients.

\section{Conclusion}

It can be concluded from the results of the present study that majority of children between age of 6-12 years and their parents prefer N20 sedation over only conventional behaviour management techniques after undergoing dental treatments employing both the techniques.

\section{References}

1. Grewal N. Implementation of behaviour management techniques--how well accepted they are today. Journal of the Indian Society of Pedodontics and Preventive Dentistry 2003;21(2):70-4.

2. Bhandari R, Thakur S, Singhal P, Chauhan D, Jayam C, Jain T, et al. Parental awareness, knowledge, and attitude toward conscious sedation in North Indian children population: A questionnaire-based study. Indian Journal of Dental Research 2018;29(5):693.

3. Desai SP, Shah PP, Jajoo SS, Smita PS. Assessment of parental attitude toward different behavior management techniques used in pediatric dentistry. Journal of Indian Society of Pedodontics and Preventive Dentistry 2019;37(4):350.

4. Nelson TM, Xu Z. Pediatric dental sedation: challenges and opportunities. Clinical, cosmetic and investigational dentistry 2015;7:97.

5. Muhammad S, Shyama M, Al-Mutawa SA. Parental attitude toward behavioral management techniques in dental practice with schoolchildren in Kuwait. Medical Principles and Practice 2011;20(4):350-5.

6. Alkandari SA, Almousa F, Abdulwahab M, Boynes SG. Dentists' and parents' attitude toward nitrous oxide use in Kuwait. Anesthesia progress 2016;63(1):8-16.

7. Almarwan M. Parental Perception toward Dental Sedation in Pediatric Patients at the University of Maryland (Doctoral dissertation) 2018.

8. Malamed SF, Clark MS. Nitrous oxide-oxygen: a new look at a very old technique. CDA 2003;31(5):397-404.

9. Gupta K, Emmanouil D, Sethi A, editors. Nitrous Oxide in Pediatric Dentistry: a clinical handbook. Springer Nature 2019 Dec 4.

10. Wright GZ, Kupietzky A, editors. Behavior management in dentistry for children. Ames: Wiley Blackwell 2014 Jan 21.

11. Hammond NI, Full CA. Nitrous oxide analgesia and children's perception of pain (Master's thesis, University 
of Iowa) 1982.

12. Chouchene F, Abdellatif A, Fatma M, Ahlem B, Fethi M, Hichem G. Conscious Sedation by the Inhalation of Equimolar Mixture of Oxygen and Nitrous Oxide in a Paediatric Dentistry Department 2020.

13. American Academy of Pediatric Dentistry, Use of nitrous oxide for pediatric dental patients', The Reference Manual of Pediatric Dentistry Chicago 2020;9:324.

14. Krishna PV, Gaur D, Ganesh M, Kumar SC. Conscious Sedation in. pediatric Dentistry: a review, IJCMR 2016;3(6):1577.

15. Kanagasundaram SA, Lane LJ, Cavalletto BP, Keneally JP, Cooper MG. Efficacy and safety of nitrous oxide in alleviating pain and anxiety during painful procedures. Archives of disease in childhood 2001;84(6):492-5.

16. Alkandari SA, Almousa F, Abdulwahab M, Boynes SG. Dentists' and parents' attitude toward nitrous oxide use in Kuwait. Anesthesia progress 2016;63(1):8-16.

17. Bhandari R, Thakur S, Singhal P, Chauhan D, Jayam C, Jain T, et al. Parental awareness, knowledge, and attitude toward conscious sedation in North Indian children population: A questionnaire-based study. Indian Journal of Dental Research 2018;29(5):693. 